\title{
Co-movements between Chinese and British metal futures markets: Some New Evidence base on DCC-GARCH model
}

\author{
Li Yang*, Jie Li \\ Institute of Quality Development, Kunming University of Science and Technology, Kunming ,China
}

Keywords: Futures market; DCC-GARCH model; price linkage.

\begin{abstract}
Based on the dynamic linkage between financial markets, taking futures Copper, Aluminum and Zinc as the research object, using the two element DCC-GARCH to study the price relationship between Chinese and British nonferrous metals futures markets. The results show that the linkage of the Sino British futures market is changing with time, which was the strongest, the dynamic linkage between the Copper market, Zinc, Aluminum is weakest, indicating that China's futures market plays a more and more important in the international futures market position.
\end{abstract}

\section{Introduction}

With the development of urbanization and industrialization, the demand for non-ferrous metal resources in China has increased rapidly, and has become the world's largest buyer of non-ferrous metals trading volume. With the rapid development of economic globalization, China's nonferrous metal futures market has been running steadily, market maturity has been improved, and remarkable progress has been made. Among them, China's Shanghai Futures Exchange (SHFE) since 1990s and non-ferrous metals futures trading, after nearly 25 years of rapid development, has been followed by the London Metal Exchange (LME) the world's second largest metal futures market after the impact in the international futures market and have become increasingly prominent role. However, due to the shortage of China's metal resources, most of them rely on imports to solve domestic demand. As the most authoritative futures market in the world, LME has the most important impact on China's SHFE market.

Therefore, the linkage of the British metal futures market through the research under the condition of open economy, could enable us to more in-depth understanding of the market operation rules of two and absorption process information, but also can provide reference for the Chinese government in the future to strengthen macro-control and make decisions on the futures market, the non-ferrous metal production and processing enterprises and metal futures investors, to provide price guidance and reduce international metal futures price change risk in the domestic market. At the same time, grasp the "The Belt and Road" strategic opportunity, steady and orderly promote the opening of China's non-ferrous metals futures market to further strengthen China's metal futures market pricing in the international market.

\section{Organization of the Text}

Data Construction. According to the listing time, non-ferrous metals futures trading volume and level of activity, the choice of the SHFE market, Shanghai and Shanghai zinc copper aluminum continuous contract closing price, respectively by CUC, ALC, ZNC, and LME market copper, aluminum and zinc in the March electronic daily closing price. Groups CUL, ALL, ZNL. The sample interval ranged from March 25, 2011 to December 31, 2015, and data from wind information. Because of the different holidays at home and abroad, taking into account the corresponding time series variables, so the pairing of the Sino British market metal futures price data by date, where there is a lack of data on the deletion of this group, so a total of 1065 groups of 
sample observations. In addition, in order to eliminate the influence of exchange rate fluctuations between metal futures price and the comparability of the data, this study uses local currency and for all data processing, get the daily logarithmic return rate, respectively by RCUC, RALC, RZNC, RCUL, RALL, RZNL. The volatility of the price return series of the same metal futures is shown in Fig 1. Descriptive Statistics of the price return series is shown in Table 1.
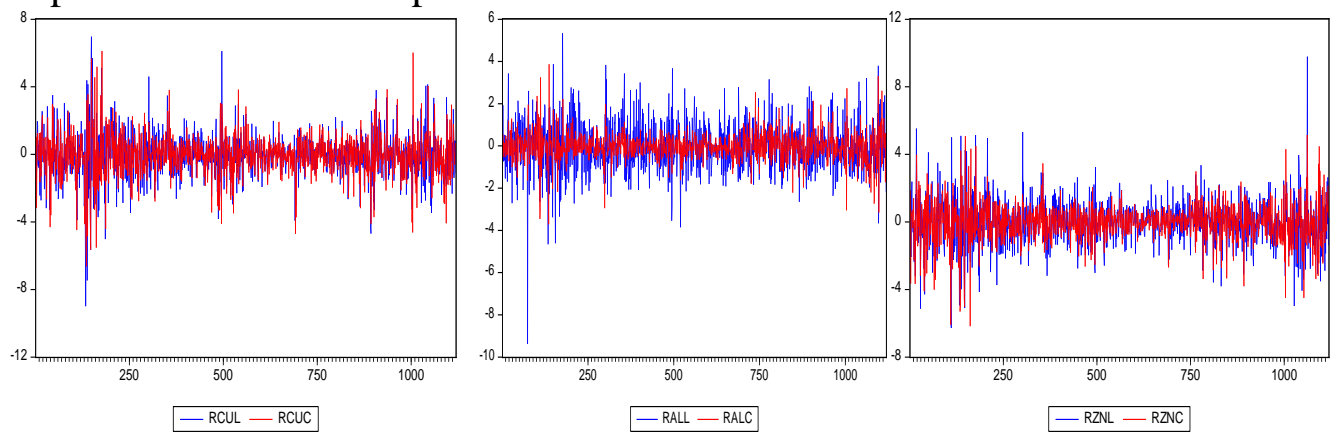

Figure 1 Volatility chart of price return of metal futures

The mean and standard deviation, for the same metal futures, SHFE market price yield mean small, large standard deviation, while the market price of SHFE yields the mean, standard deviation, which reflects the LME market on the metal futures price changes more sensitive information, transaction risk is greater; on the other hand also SHFE stable development of the market, which is closely related to our government macro-control and strict supervision of the futures market. From skewness and kurtosis, the skewness of the futures price returns is different from 0 , only the London zinc right bias, the rest are left biased, and the kurtosis is greater than 3 , with asymmetric distribution and significant "peak thick tail" characteristics. The results of the JB normal test are very high, which further confirms that the price earnings sequence does not obey the normal distribution. The ADF test results show that the real sequence of the futures price returns is stable at $1 \%$ of the significant level. Q (12) and Q2 (12) was significantly different from zero, suggesting that the sequence and sequence of square metal futures market gains in Britain was the presence of volatility clustering phenomenon and significantly in Figure 1 the judgment consistent, therefore, the data features suitable for using the DCC-GARCH model to explain the volatility clustering phenomenon.

Table 1 Basic statistics of price returns

\begin{tabular}{cccccrr}
\hline & RCUL & RALL & RZNL & RCUC & RALC & \multicolumn{1}{c}{ RZNC } \\
\hline Mean & -0.0638 & -0.0445 & -0.0375 & -0.0614 & -0.0410 & -0.0344 \\
Std. Dev. & 1.3845 & 1.2028 & 1.4350 & 1.2923 & 0.6938 & 1.1853 \\
Skewness & -0.1854 & -0.2136 & 0.1599 & -0.2716 & -0.1047 & -0.4022 \\
Kurtosis & 7.1808 & 6.7254 & 6.2704 & 6.7894 & 8.0248 & 6.9195 \\
Jarque-Bera & 820.65 & 655.03 & 503.00 & 682.66 & 1173.20 & 745.80 \\
ADF & $-34.414 * * *$ & $-34.977 * * *$ & $-34.118 * * *$ & $-34.251 * * *$ & $-35.092 * * *$ & $-36.105 * * *$ \\
Q (12) & $36.009 * * *$ & $30.919 * * *$ & $29.5641 * * *$ & $340.73 * * *$ & $71.895 * * *$ & $42.338 * * *$ \\
Q $^{2}(12)$ & $495.25 * * *$ & $193.653 * * * 347.054 * * * 305.800 * * *$ & $255.55 * * *$ & $282.180 * * *$ \\
\hline
\end{tabular}

* Significant at 10\% level, ** Significant at 5\% level, *** Significant at 1\% level; () is z-statistics.

Modeling dynamic conditional correlation. Most previous works that assess time-varying correlation between markets rely on the multivariate DCC model developed by Engle This model is suitable to assess co-movements between the markets we study because it can reflect the influence between variables efficiently. In order to analyze the influence between LME and SHFE nonferrous metals prices, we adopt DCC-GARCH model to measure the interaction effect of prices between these two markets. Assuming all the nonferrous metals prices follow multivariate normal distribution, we have $r_{t} \mid \Omega_{t-1} \sim N\left(0, H_{t}\right)$. The DCC-GARC-GARCH model can be presented as follows: 


$$
\begin{aligned}
& D_{t}=\operatorname{diag}\left(\sqrt{h_{i, j, t}}\right) \\
& R_{t}=\operatorname{diag}\left(\sqrt{q_{i, j, t}}\right) Q_{t} \operatorname{diag}\left(\sqrt{q_{i, j, t}}\right) \quad(2) \\
& Q_{t}=\left(q_{i, j, t}\right)=(1-\alpha-\beta) \bar{Q}+\alpha\left(\mu_{i, t-1} \mu^{\prime}{ }_{j, t-1}\right)+\beta Q_{t-1} \\
& h_{i i, t}=\omega_{i}+\sum_{j=1}^{q} a_{i j} \varepsilon_{i, t-1}^{2}+\sum_{j=1}^{p} \beta_{i j} h_{t t, t-j} \text { (4) }
\end{aligned}
$$

Where, $\mu_{i t}=\varepsilon_{i t} / \sqrt{h_{i i t}}, i=1,2, \cdots N ; \quad \bar{q}_{i j}=\frac{1}{n} \sum_{i=1}^{n} \varepsilon_{i t} \varepsilon_{j t} ; \quad \bar{Q}=T^{-1} \sum_{t=1}^{T} u_{t} u_{t}^{\prime} ; \quad Q_{t}$ is a single variable to estimate the conditional covariance matrix of standardized residuals; $\bar{Q}$ is $\mathrm{N}^{*} \mathrm{~N}$ unconditional variance covariance matrix. $\alpha$ and $\beta$ are the coefficients of DCC-GARCH model, satisfying $\alpha>0, \beta>$ 0 , and $\alpha+\beta<1$ 。 The conditional correlation coefficient $\rho_{i, j, t}$ between two markets .i and $\mathrm{j}$ is then expressed by the following equation:

$$
\rho_{i j, t}=\frac{(1-\alpha-\beta) \bar{q}_{i j}+\alpha\left(\mu_{i, t-1} \mu_{j, t-1}\right)+\beta q_{i j, t-1}}{\sqrt{\left.(1-\alpha-\beta) \bar{q}_{i i}+\alpha\left(\mu_{i t-1}^{2}\right)+\beta q_{i, t-1}\right)\left((1-\alpha-\beta) \bar{q}_{j}+\alpha\left(\mu_{j, t-1}^{2}\right)+\beta q_{j, t-1}\right)}}
$$

Accordingly, the estimation of the DCC-GARCH model as described above is can be estimated using a two-stage procedure. In the first stage, univariate $\mathrm{GARCH}(1,1)$ model is estimated for each time series. During the second stage, the transformed residuals from the first stage (i.e., the estimated residuals are standardized by their conditional standard deviations) are used to infer the conditional correlation estimators. The log-likelihood of the observations on $t \varepsilon$ is given by

We estimate the parameters of the DCC model by two steps,

The first step is to identify and estimate the single variables of each residual sequence. The GARCH effect, second step, is normalized in each residual sequence. On the basis of the maximum likelihood estimation, the dynamic correlation structure is used. According to the above definition and hypothesis, logarithm can be used as a parameter. The natural function is expressed as following.

$L=-\frac{1}{2} \sum_{t=1}^{T}\left(n \lg (2 \pi)+2 \lg \left|D_{t}\right|+\lg \left|R_{t}\right|+\varepsilon_{t-1}^{\prime} R_{t}^{-1} \varepsilon_{t-1}\right)$

Empirical Findings of the analysis. The use of DCC-GARCH model to study the market on the same metal futures returns, we estimate by two steps, the first step, single variable GARCH $(1,1)$ to model the mean equation residuals of the metal futures return rate, parameter estimation results are shown in Table1; the second step, based on the residual series standard the parameter estimation of dynamic correlation, using the maximum likelihood, as shown in Table 2

Table 3 Results of parameter estimation of univariate GARCH model

\begin{tabular}{ccccccc}
\hline & RCUL & RALL & RZNL & RCUC & RALC & RZNC \\
\hline$\omega$ & $3.45 \mathrm{E}-06$ & $4.11 \mathrm{E}-05$ & $1.13 \mathrm{E}-06$ & $4.71 \mathrm{E}-06$ & $4.73 \mathrm{E}-07$ & $8.01 \mathrm{E}-07$ \\
$\alpha$ & 0.079 & 0.173 & 0.038 & 0.083 & 0.136 & 0.083 \\
$\beta$ & 0.898 & 0.596 & 0.955 & 0.875 & 0.853 & 0.913 \\
$\alpha+\beta$ & 0.977 & 0.769 & 0.993 & 0.928 & 0.989 & 0.996
\end{tabular}

\begin{tabular}{cccc}
\hline \multicolumn{4}{c}{ Table 4 Results of parameter estimation of DCC-GARCH model } \\
\hline & RCUL-RCUC & RALL-RALC & RZNL-RZNC \\
\hline $\operatorname{DCC}(\alpha)$ & $0.032^{* * *}$ & $0.005^{* *}$ & $0.008^{* * *}$ \\
& {$[2.049]$} & {$[2.111]$} & {$[2.752]$} \\
$\operatorname{DCC}(\beta)$ & $0.964^{* * *}$ & $0.937^{* * *}$ & $0.970^{* * *}$ \\
& {$[211.350]$} & {$[74.642]$} & {$[252.224]$} \\
$\operatorname{DCC}(\alpha+\beta)$ & 0.996 & 0.942 & 0.978 \\
\hline
\end{tabular}

As shown in Table 2, the parameter alpha and beta are significantly different from zero, indicating that the DCC-GARCH model can obtain effective external information, and the model works well. The greater the dynamic conditional variance coefficient beta of DCC model, the 
greater the dynamic correlation coefficient change, the greater the alpha plus beta, indicating that the stronger the dynamic correlation is, the higher the degree of market integration is. According to the above standard, can be seen in the metal futures market closely, has certain correlation, especially the copper futures market, the dynamic correlation coefficient is up to around 0.9 , higher than the futures market and the dynamic correlation between the aluminum zinc market. This is because the futures copper market in China has developed relatively mature, and the linkage with the international financial market is more and more significant. In contrast, due to aluminum and zinc futures development later, and later into the international metal futures market, and China's aluminum industry overcapacity serious, dominant position in general than the copper market in the world.
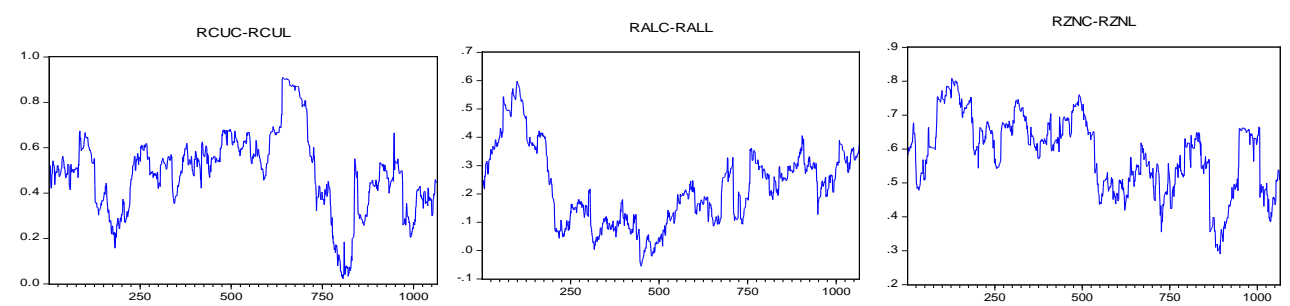

Figure 2 Dynamic correlation coefficient diagram

In addition, combined with the dynamic correlation coefficient can be seen in Fig 2, in the entire sample period, the dynamic conditions in metal futures market correlation coefficient showed significant changes in variability; path, frequency and amplitude of dynamic correlation coefficient between fluctuation of copper market is higher than that of aluminum and zinc market. This progress reflects the linkage between China and the UK copper market is more significant than the aluminum and zinc market.

\section{Literature References}

With the integration of world financial markets, the price linkage of commodities traded on different financial markets has become a hot issue among scholars both at home and abroad, especially the relationship between Chinese and British metal futures market prices. According to the previous research, different scholars have made some studies on the relationship between the British metal futures market price from different angles, but most scholars confined to the domestic and foreign metal futures market price between the long-term equilibrium relationship or short-term volatility spillover effects [1,2,3]. However, because the correlation coefficient between financial markets is dynamic, only the single model methods such as VAR and GARCH can not effectively analyze the dynamic time-varying relationship between them. The dynamic conditional multivariate GARCH model proposed by Engle is a good solution to this problem, and has been confirmed in relevant studies in [4]. The domestic scholar Hu Dongbin (2012) was studied using the DCC-GARCH model for the dynamic correlation between metal futures and foreign exchange, money market, found a certain dynamic correlation between metal futures market and foreign exchange market, but is not very strong, no obvious correlation between dynamic [5] and money market between. Wang Hao (2016) using DCC-GARCH Japan stock market and China, South Korea, the United States, Britain and other stock markets in different stages of volatility spillover effect [6]. Liu Suyun (2016) by DCC-GARCH on the domestic soybean futures market and the spot market price is studied, found between the fluctuation with non symmetry, showed a skewed distribution, and increases with the speed fluctuation amplitude attenuation gradually slow down [7].

Therefore, this paper takes the Chinese and British nonferrous metals futures copper and aluminum as the research object, and uses the two element DCC-GARCH model to analyze the transitive relationship of the dynamic volatility of the two markets. Finally, combining the two conclusions, we analyze the dynamic correlation between the futures prices of Sino British nonferrous metals futures market. 


\section{Summary}

With the help of DCC-GARCH model, the linkage effect of nonferrous metals prices between Chinese and British metal futures markets is discussed in detail. By the DCC model parameters, we can find that the dynamic conditional correlation coefficient of the same metal futures price in LME and SHFE markets shows significant time-varying, showing the characteristics of volatility clustering. Among them, the most dynamic copper market prices, volatility clustering is the strongest; for the metal zinc, dynamic correlation between LME and SHFE the two market after copper; in contrast, the dynamic correlation between weak domestic aluminum market. Overall, there is a stable and continuous linkage between China's metal futures market and the international futures market prices.

\section{References}

[1] Li Shanle. Chinese Shanghai and London futures price returns: An Empirical Analysis of copper futures as an example of modern commercial [J]., 2011, (09): 190-191.

[2] Gao Hui, Zhao Jinwen. Empirical Study on futures price return and Volatility -- a case study of [J]. in China, Shanghai and London, UK, 2007, (02): 54-66.

[3] Guo Shuhua, Wang Hua, Gao Bo, Wang Lixian. The metal futures market price fluctuations and the linkage relation research -- Research on international financial cases of [J]. with SHFE and LME copper was 2010 (04): 79-88.

[4] Engle, R. F. Dynamic Conditional Correlation: A Simple Class of Multivariate Generalized Autoregressive Conditional Heteroske dasticity Models. Journal of Business \&amp; Economic Statistics, 2002, (20): 339-350.

[5] Hu Dongbin, Zhang Zhanying. Study on the dynamic correlation between metal futures market and foreign exchange and money market based on DCC-GARCH model [J]. mathematical statistics and management, 2012, (05): 906-914.

[6] Wang Hao. Analysis of volatility spillover effect between Japanese stock market and international market based on DCC-GARCH model [J]. modern Japanese economy, 2016, (05): 27-37.

[7] Liu Suyun, Han Yijun, Bao Limin. Dynamic correlation analysis of soybean market at home and abroad under the background of price support policy reform -- Based on Bayesian DCC-GARCH model [J]. agricultural technology and economy, 2016, (08): 72-84. 